\title{
REVIEW \\ Etiology of spinal cord injuries in Sub-Saharan Africa
}

\author{
N Draulans, C Kiekens, E Roels and K Peers
}

\section{Study design: Review.}

Objectives: The aim is to highlight the epidemiology of spinal cord injuries (SCls) in Sub-Saharan Africa in order to improve prevention strategies.

Setting: University Hospitals Leuven, Belgium.

Methods: Pubmed was searched over August and September 2010. A combination of the following MeSH-terms was used: 'Africa South of the Sahara', 'Spinal Cord Diseases', 'Paraplegia' and 'Spinal Cord Injuries'. Limits were set on articles published as from 1990. The World Health Organization database was also consulted.

Results: We obtained 243 hits of which 13 articles were relevant to the case. These papers covered seven countries: Ethiopia, Ghana, Nigeria, Senegal, Sierra Leone, South Africa and Zimbabwe. In traumatic SCIs, motor vehicle accidents are the most frequent cause of injury followed by falling from a height and thirdly violence, being the most important cause of SCl in South Africa. In the Plateau State of Nigeria, collapsing tunnels in illegal mining are the most prevalent cause. For the non-traumatic SCls, tuberculosis appeared to be the most important cause, followed by malignant illnesses. Human immunodeficiency virus (HIV) serology tests were only available in the article concerning Ethiopia. Relatively more men were involved in traumatic SCls and the average age was higher in the nontraumatic than in the traumatic group.

Conclusion: Although literature on the subject is scarce, prevention should focus on road-safety, tuberculosis and HIV. Standardized registration of $\mathrm{SCl}$ is needed for prevention and further research. The use of the current International SCl core data set should be encouraged worldwide as a uniform classification method.

Spinal Cord (2011) 49, 1148-1154; doi:10.1038/sc.2011.93; published online 11 October 2011

Keywords: etiology; spinal cord injury; paraplegia; Africa South of the Sahara

\section{INTRODUCTION}

Spinal cord injury (SCI) is a condition with a devastating impact on the physical, mental and social life of often young persons. It also represents a considerable financial cost to society and family. Epidemiological and etiological knowledge about SCI is essential for designing and focusing prevention campaigns. Especially in the Sub-Saharan countries, this knowledge is warranted as on average less means and financial resources are available, not only for preventative strategies but also for treatment and rehabilitation.

SCI is most often referred to as traumatic or non-traumatic. In worldwide reviews, traumatic SCI annual incidence rates yield values from 12.1 to 57.8 cases per million with motor vehicle accidents (MVAs), falls, violence and sports being the leading causes. ${ }^{1-4}$

Compared with traumatic SCI very little is known on the incidence and etiology of non-traumatic SCI, presumably in part because of the often progressive onset of the lesion.

Data on Sub-Saharan Africa (SSA) are seldom mentioned in these worldwide reviews. Only Ackery et al. ${ }^{2}$ and Cripps et al. ${ }^{4}$ mentioned articles concerning the etiology of traumatic SCI in SSA, but they did not discuss the non-traumatic causes. Therefore, a search purely focused on SSA seemed necessary to try to close this gap in literature. The collection of these data may help to highlight the main bottlenecks and to focus on prevention of SCI in SSA, using the limited means as efficiently as possible.

\section{METHODS}

Search strategy

Literature was browsed in the period of August and September 2010, using PubMed and a combination of the following MeSH terms: 'Africa South of the Sahara, 'Spinal Cord Diseases', 'Paraplegia' and 'Spinal Cord Injuries'. 'Africa South of the Sahara' was combined with each of the other MeSH terms. Articles with as a main subject polio (NOT 'Poliomyelitis' (Majr)) were discarded as this illness is not causing a spinal cord lesion as such. For each MeSH-term several subheadings were selected. No language restrictions were necessary as all the articles found were in English or French. The search function was limited to 'articles published as from the year 1990' and 'humans'. This list subsequently was searched through looking for relevant articles and the literature survey was completed making use of a list of related articles on PubMed and the reference lists of each relevant article.

\section{Inclusion criteria}

The papers were selected as relevant on basis of the following criteria: presence of data on incidence or etiology of traumatic or non-traumatic SCI in a SubSaharan country. As no articles reported incidence rates at population level in a Sub-Saharan country, articles based on hospital admissions were included additionally.

\section{Exclusion criteria}

Articles of which the full text could not be obtained and case reports were excluded. As for content, articles focusing only on cervical lesions or penetrating trauma or pediatric population were excluded as these articles did not give an overview of the etiology of SCI in general. 
Furthermore, the World Health Organization (WHO) data base has been consulted concerning the evolution of prevalence of tuberculosis. The web was also explored for any relevant article or association that could offer more information on the subject.

\section{RESULTS}

Browsing literature yielded 243 articles, each of them referring to related articles of which in the end only 13 appeared to be both relevant and available. A flowchart for the selection of articles included in this review is provided in Figure 1 and Table 1 shows an overview of the retained articles. The selected articles report mainly in a retrospective way, numbers and etiologies of either traumatic or nontraumatic spinal cord lesions. In each case, the population consists of patients registered at a specific hospital during a specific period of time meaning these are referral-based and not population-based studies.

As all studies clearly distinguish traumatic and non-traumatic spinal cord lesions, Figure 2 shows the etiologies of traumatic SCI and Figure 3 of the non-traumatic SCI.

In most of the retrieved articles, additional information on the epidemiology of SCIs was available and it was summarized in Table 2 by the investigator, giving the percentage of paraplegia and tetraplegia, sex distribution, age and percentage of complete and incomplete lesions often using the Frankel-scale.

\section{Etiology of traumatic SCIs}

Nine articles on traumatic SCIs concerning five Sub-Saharan countries (Nigeria, Senegal, Sierra Leone, South Africa and Zimbabwe) were included.

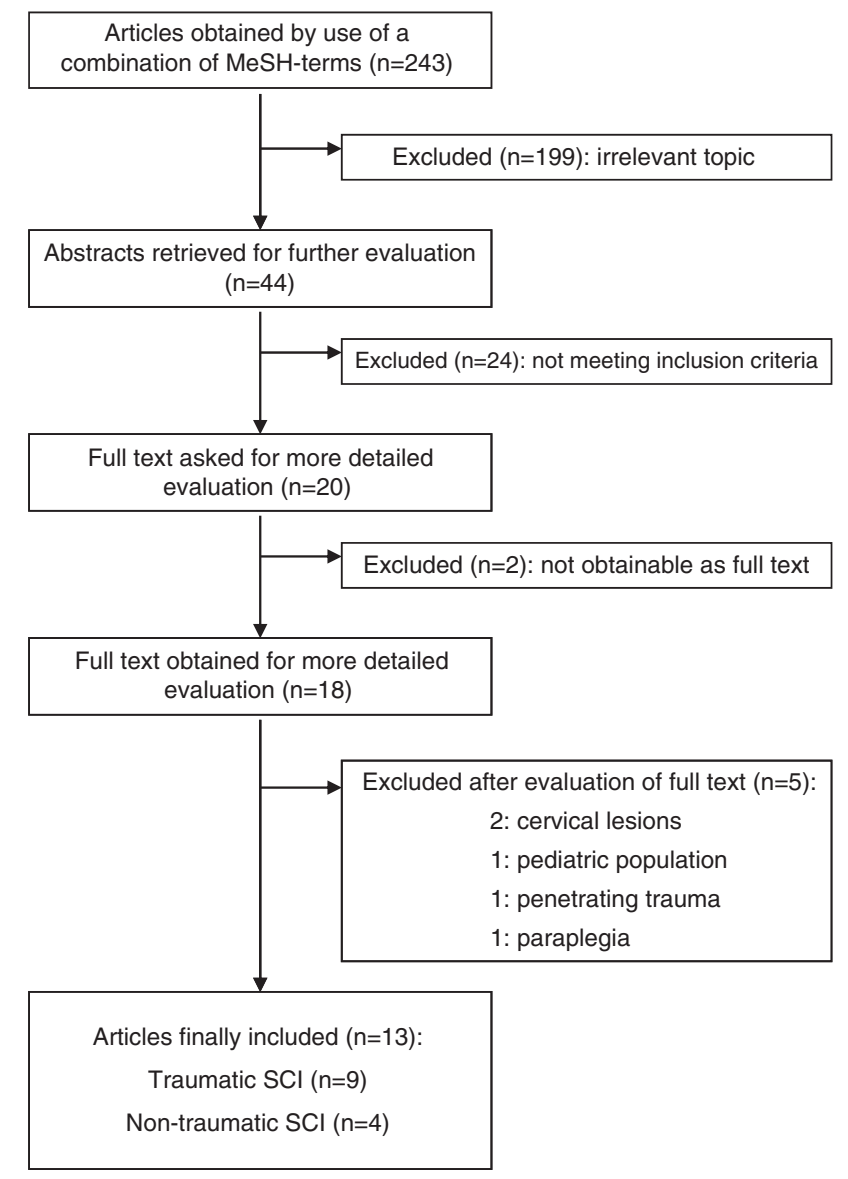

Figure 1 Flow diagram of the systematic literature review.
Our search produced four Nigerian articles. Igun et al. ${ }^{5}$ described the epidemiology of 68 traumatic spinal injuries, of which 56 had a spinal cord lesion. Vehicular accidents (49\%) were the main cause and collapsed tunnels (cave-in injuries in illegal mining) were second in line $(26 \%)$. Other important causes were falls from a height $(19 \%)$ and gunshot wounds (6\%). In all, $77 \%$ of the patients with a spinal cord lesion had a complete lesion (=Frankel A). The hospital mortality after 30 days was $26 \%$, among which patients suffering tetraplegia doubled in number those suffering paraplegia.

Solagberu $^{6}$ analyzed retrospectively the data of 39 patients with traumatic SCI. In total, $67 \%$ were due to traffic accidents and $23 \%$ due to falling from a tree. In $46 \%$, there was a cervical lesion. In all, $69 \%$ of the patients sustained a complete lesion. Out of 10 persons not surviving the SCI, 9 had been transferred to various centers before being admitted to this hospital.

Olasode et al. ${ }^{7}$ systematically collected data of 71 patients. In all, 63 cases $(89 \%)$ were due to traffic accidents, 2 cases were caused by falling from palm trees $(3 \%)$ and 3 cases (4\%) were due to violence (strangulation, gunshot).

Obalum et al. ${ }^{8}$ analyzed retrospectively the data of 468 patients with traumatic SCI. In all, 77\% were due to road traffic accidents, $11 \%$ were related to violence and $9 \%$ were related to falls. At presentation $92 \%$ of the patients had an AIS grade A. At discharge, AIS grade A represented $49 \%$ of the patients and $18 \%$ had died in the meanwhile.

An article from Senegal, Seye et al. ${ }^{9}$ reported on 496 traumatic spinal injuries treated at the University Hospital of Dakar. Falling from great height was the most frequent cause (49\%) followed by traffic accidents with $44 \%$. Sport accidents represented $6 \%$ of the traumata.

As for Sierra Leone, Gosselin and Coppotelli ${ }^{10}$ described the epidemiology of 24 patients who were admitted with traumatic SCI. Twelve patients sustained a road traffic accident (50\%) while in 10 patients the cause of the SCI was a fall $(41 \%)$. A total of 21 patients had a complete lesion at admission versus only 3 patients with an incomplete lesion.

Levy et al. ${ }^{11}$ from Zimbabwe, described the etiology of 136 SCI cases and reported a high incidence of traffic accidents (56\%). Less important causes were falling from trees $(11 \%)$, and violence $(15 \%$ including gunshot and stab wounds).

Another two selected articles dealt with South-African SCI. Hart and Williams ${ }^{13}$ reviewed the files of 616 SCI patients and reported that traumatic SCI represented $89 \%$ of the total number of SCI in that period. Violence $(56 \%)$ was by far the most frequent cause, followed by MVAs (25\%) and falls from heights $(2.5 \%)$. Velmahos et al. ${ }^{12}$ collected data in two hospitals of which one was also used by Hart and Williams. ${ }^{13} \mathrm{He}$ reported on $551 \mathrm{SCI}$ patients and violence was mentioned to be the most common cause (gunshot wounds 35\%, stab wounds $26 \%$, followed by traffic accidents $30 \%$ ).

\section{Etiology of non-traumatic SCIs}

Only four papers on non-traumatic SCI etiology were found, originating from four different countries as mentioned in Table 1 . Table 3 shows the different diagnostic methods that were available in the hospitals.

A study in Ethiopia from Zenebe ${ }^{14}$ stated tuberculous spondylitis was the main cause of non-traumatic SCI (27\%), followed by human immunodeficiency virus (HIV)-1-associated myelopathy (17\%). Other important causes were metastatic cord compression (15\%), tropical spastic paraparesis (14\%), cervical spondylosis (9\%) and primary cord tumors (9\%).

Nyame $^{15}$ in Ghana collected prospectively data from 64 patients suffering from non-traumatic paraplegia treated at the Korle $\mathrm{Bu}$ 
Table 1 Literature survey

\begin{tabular}{|c|c|c|c|c|}
\hline Country & Authors & Study & Setting & Number of patients \\
\hline \multicolumn{5}{|l|}{ Traumatic } \\
\hline Nigeria & Igun et al. ${ }^{5}$ & 1984-1997 & Retrospective. Hospital setting & 68 \\
\hline Nigeria & Solagberu $^{6}$ & 1995-1999 & Retrospective. Hospital setting & 39 \\
\hline Nigeria & Olasode et al. ${ }^{7}$ & 18 months & Prospective. Hospital setting & 71 \\
\hline Nigeria & Obalum et al. ${ }^{8}$ & 1992-2006 & Retrospective. Hospital setting & 468 \\
\hline Senegal & Seye et al. ${ }^{9}$ & 1980-1988 & Retrospective. Hospital setting & 496 \\
\hline Sierra Leone & Gosselin and Coppotelli ${ }^{10}$ & 2000-2004 & Retrospective. Hospital setting & 24 \\
\hline Zimbabwe & Levy et al. ${ }^{11}$ & 1988-1994 & Retrospective. Hospital setting & 136 \\
\hline South Africa & Velmahos et al. ${ }^{12}$ & 1988-1992 & Retrospective. Hospital setting & 551 \\
\hline South Africa & Hart and Williams ${ }^{13}$ & 1988-1993 & Retrospective. Hospital setting & 616 \\
\hline \multicolumn{5}{|l|}{ Non-traumatic } \\
\hline Ethiopia & Zenebe $^{14}$ & 1990-1993 & Retrospective. Hospital setting & 130 \\
\hline Ghana & Nyame ${ }^{15}$ & 1991-1994 & Prospective. Hospital setting & 64 \\
\hline Nigeria & Ogunniyi et al. ${ }^{16}$ & 1988-1993 & Retrospective. Hospital_setting & 104 \\
\hline Zimbabwe & Parry et al. ${ }^{17}$ & 1989-1994 & Retrospective. Hospital setting & 159 \\
\hline
\end{tabular}

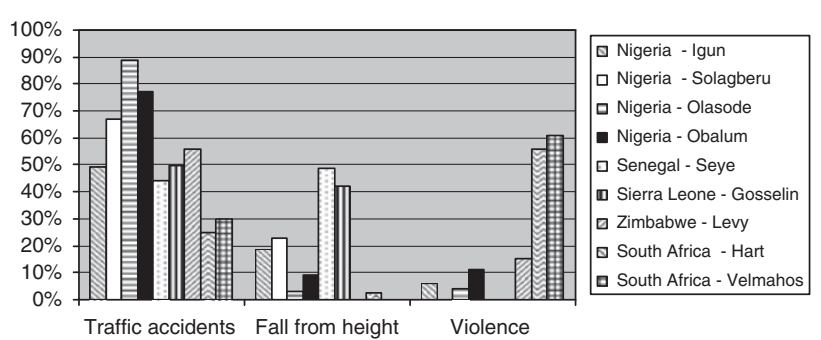

Figure 2 Causes of traumatic SCl in SSA.

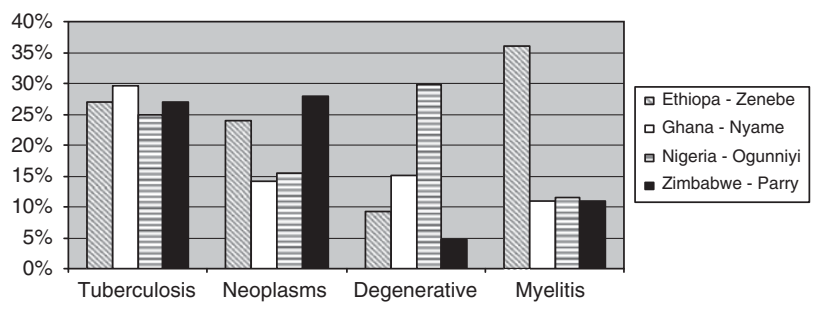

Figure 3 Causes of non-traumatic SCl in SSA.

Teaching Hospital. The most common cause appeared to be tuberculosis $(30 \%)$, followed by neoplastic lesions (14\%) and degenerative diseases such as cervical spondylosis with myelopathy (13\%) and motor neuron diseases (6\%). Transverse myelitis and the GuillanBarré syndrome (however, a Guillain-Barré syndrome is not a SCI) were mentioned additionally, each of them representing $11 \%$. We must mention, however, that motor neuron disease and GuillainBarré syndrome cannot be considered as an SCI.

Ogunniyi et al. ${ }^{16}$ collected and retrospectively analyzed data from 104 patients registered at the University College Hospital in Niger from 1988 to 1993 . Spondylotic myelopathy appeared to be the main cause $(29.8 \%)$, tuberculous myelopathy was the second most important cause $(25 \%)$, followed by neoplasms (15\%) and transverse myelitis (12\%).

Parry et al. ${ }^{17}$ examined the etiology of 159 non-traumatic SCI in the population of Zimbabwe. The most frequent cause of non-traumatic
SCI was neoplasm (28\%), one-third of them being metastatic. Tuberculosis represented $27 \%$ of the causes. Of these 43 patients, 4 patients died, 27 regained mobility (walk unassisted or with mechanical aids) and 11 remained paraplegic. One patient was lost to followup. The investigators mentioned that the part represented by tuberculosis could be falsely low in this study, as it concerns a tertiary center and these patients can often be treated in the local hospital. Transverse myelopathy of unknown origin and Guillain-Barré (not a SCI) represented $11 \%$ and $6 \%$ of the causes, respectively.

One year after discharge from hospital, $48 \%$ of the patients were still alive, meanwhile the death of $18 \%$ had been confirmed. In all, $44 \%$ was lost to follow-up. The investigators warn for the expected increase in HIV-related myelopathy.

\section{DISCUSSION}

To our knowledge, this review is the first attempt to make a survey of the etiology of SCIs focused on SSA over the last 20 years. In spite of many obvious obstacles, such as scarcity and age of data, incomplete data and absence of a uniform classification system, the following items may be worthwhile considering.

\section{Incidence and prevalence}

In spite of a thorough literature search no trustworthy data could be found concerning incidence and prevalence of spinal cord lesions in SSA. The studies reported always took place in a hospital context and none of them provided a survey of all admissions over the country. Correct data can only be obtained when the admission data of the country at large are at disposal and at the same time, the number of patients who never reached the hospital, can be estimated.

The most recent worldwide survey on the incidence of SCI shows clearly that even in Western countries systematic collection of these data is a problem. Van den Berg et al. ${ }^{1}$ states that values of annual incidence rates range from 12.1 to 57.8 cases per million population, respectively, in the Netherlands and Portugal.

\section{Etiology of traumatic SCIs}

When performing a critical appraisal of the studies found, we conclude that although the information seems important, it is not clear whether it is valid. As mentioned before, all studies are referral 
Table 2 Epidemiological data

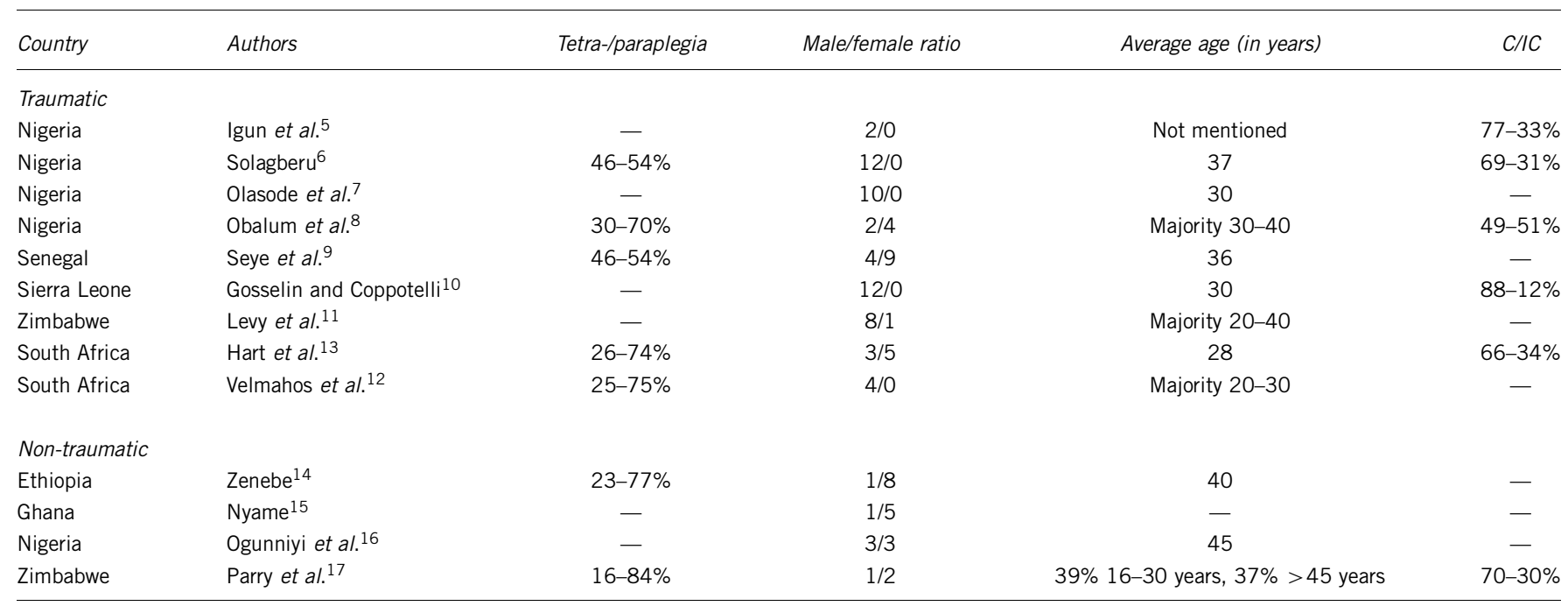

Abbreviation: C/IC, complete/incomplete lesion.

Table 3 Technical examinations

\begin{tabular}{|c|c|c|c|c|}
\hline Examinations & Ethiopia & Ghana & Nigeria & Zimbabwe \\
\hline Full blood profile & $x$ & $x$ & $x$ & $x$ \\
\hline Biochemics & & $x$ & & $x$ \\
\hline Sedimentation erythrocytes & $x$ & $x$ & $x$ & $x$ \\
\hline Protein electrophoreses & & $x$ & & \\
\hline Bacteriology & & $x$ & & $x$ \\
\hline VDRL-test (Syphilis) & & $(x)$ & & \\
\hline HTLV-1 antibody test (TSP) & $?$ & NOT & & \\
\hline HIV-1 serology test (AIDS) & $x$ & & & $x$ \\
\hline Mantoux (tuberculosis) & & $(x)$ & & $x$ \\
\hline Sputum sample (tuberculosis) & $x$ & & & \\
\hline Bence-Jones proteins & & $x$ & & \\
\hline Anatomopathology & $x$ & $x$ & $x$ & $x$ \\
\hline Radiography & $x$ & $x$ & $x$ & $x$ \\
\hline Myelography & $x$ & $x$ & $x$ & $x$ \\
\hline CT and MRI & & & $x$ & \\
\hline Lumbar puncture & $x$ & $x$ & & \\
\hline Marrow puncture & $x$ & $x$ & $x$ & \\
\hline Electroencephalogram & & $x$ & & \\
\hline
\end{tabular}

Abbreviations: AIDS, acquired immune deficiency syndrome; CT, computed tomography; HIV, human immunodeficiency virus; HTLV-1, human T-cell lymphotropic virus type 1; MRI, magnetic resonance imaging; NOT, for certain test not possible; TSP, tropical spastic paraparesis; VDRL-test, Venereal Disease Research Labarotory Test; $\mathrm{x}$, test possible; (x), test not always possible.

and not population based, which leads inherently to a bias. The studies used were published as from 1990, meaning that etiology and epidemiology may have evolved, which stresses the need for concurrent reporting with recent data.

Comparing etiologies in the different countries, some tendencies become apparent. The most recurrent categories in the articles describing the etiology of spinal traumata and traumatic spinal cord lesions in SSA, are road traffic accidents, falls from heights and gunshot and stab wounds (Figure 2).

Road traffic accidents are the most common cause of traumatic spinal cord lesions. There are several explanations to this. In many African countries, there is a rapid increase in the number of vehicles without infrastructure being adapted. Moreover, many vehicles are not equipped with safety belts and transport of people in open lorries is very common. ${ }^{7}$

'Falls from height' are generally less frequent than traffic accidents. In Senegal, however, the former category is the most important one, without a clear explanation to this. And while in Europe and the United States, categorizing falls depends on whether or not the fall is a labor accident, in Nigeria categorizing is made according to the type of tree the patient fell from. . $^{6,7}$

In South Africa, 'violence' is an important category, to such an extent that the articles distinguish separate categories of stab wounds and gunshot wounds. ${ }^{12,13}$ It should be mentioned that both the included hospitals were situated near a township, characterized by an above average degree of violence, mentioned by the investigators. Both studies may have partially used the same data.

Furthermore, there was the striking category 'collapsing tunnels' in the Plateau State of Nigeria, a region with a lot of illegal mining. ${ }^{5}$ This category shows us that there are great differences among countries, but also between economically different regions.

Other rare causes are suicide attempts by strangulation, sports and carrying heavy burdens on the head.

A study from the United States of America by McKinley ${ }^{18}$ concluded that MVAs constitute the main cause of SCI with $22 \%$, followed by falls and gunshot injuries with respectively $19 \%$ and $16 \%$ (Figure 4).

The worldwide review by Van den Berg et al. ${ }^{1}$ (not containing information on SSA) confirmed that MVA are the largest cause in the majority of the reviewed studies. Some studies showed, however, almost equal percentages for MVA as for falls (mainly elderly).

\section{Etiology of non-traumatic SCIs}

As far as the non-traumatic SCI are concerned, most articles distinguish between infectious or inflammatory causes, degenerative diseases of the spine and malignancies. Tuberculosis-related diseases of the vertebral column constitute, in view of their high incidence, a separate category (Figure 3).

For the non-traumatic causes, besides the fact that the studies are again referral based, differences in diagnostic methods should be taken into account. Not all hospitals have the same technical examination methods at hand and it is not always clearly indicated how the 


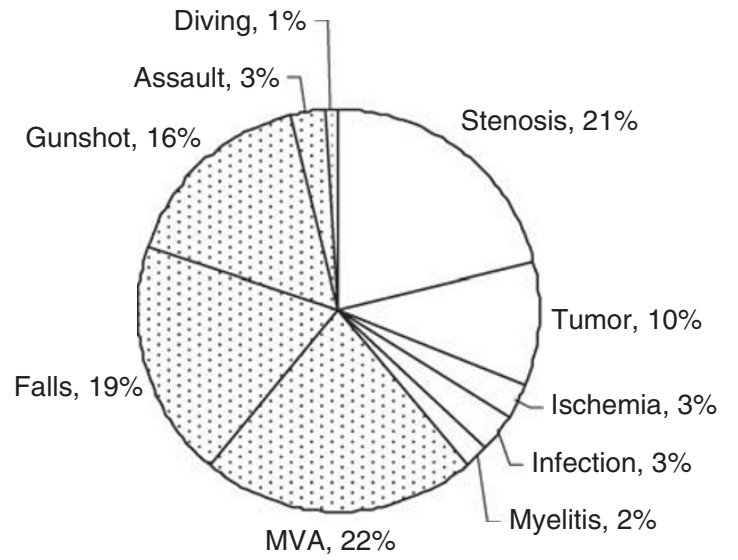

Figure 4 Causes of traumatic and non-traumatic $\mathrm{SCl}$ in the United States of America. ${ }^{18,19}$

reported diagnosis has been established. A survey of the used technical examinations can be found in Table 3. It should also be recognized that some articles included other neurological diseases such as the Guillain-Barré syndrome and motor neuron diseases.

Spinal tuberculosis is apparently the primary cause of non-traumatic spinal cord lesions in SSA and, together with neoplasms, represents almost half of the causes. Diagnosis is not, such as is the case in Europe, confirmed by a computed tomography-guided puncture, but by the clinical image, suspicious lung or skeletal lesions on plain radiographies, a positive Mantoux-test or sputum culture. The accuracy of the numerical data may be questioned, but even taking into account a certain margin of error, the importance of tuberculosis in the etiology of non-traumatic spinal cord lesions is clear.

In Europe and the United States, the percentage of neurological recovery after spinal tuberculosis is $90 \%$ as a consequence of the rapid initiation of treatment, the reasonable cost for the patient and the better therapy compliance during 12 months. $^{20}$

The used data are dating from the late eighties and early nineties, and the evolution of prevalence of tuberculosis is indicated in Figure 5, based on WHO data. ${ }^{21}$ The data show that tuberculosis is insufficiently controlled, presumably in part because of the increasing prevalence of HIV (Figure 5, Table 4).

The historical work of Brown ${ }^{22}$ on non-traumatic paraplegia in SSA, published in 1979 , learns us that in that period tuberculosis was known as the most important cause of non-traumatic SCI in Senegal, Nigeria and Malawi. It accounted for $30 \%$ of the non-traumatic SCI.

Only in the study of Zenebe ${ }^{14}$ in Ethiopia, there was an almost routine screening on HIV (Table 3). According to this group, almost $17 \%$ of non-traumatic spinal cord lesions would be secondary to HIV. This contributes to the high part of myelitis as a cause of nontraumatic spinal cord lesions in this article (Figure 3). In most studies, there was no HIV screening available (Table 3 ). This means that the number of HIV-positive tuberculosis patients and the number of patients suffering spinal cord lesions as a consequence of HIV are not known.

Spinal cord lesions in HIV patients may be due to vacuolar myelopathy or to compression by HIV-associated neoplasms or opportunistic infections. Considering that in the United States $30 \%$ of the persons dying from acquired immune deficiency syndrome presented a vacuolar myelopathy and that in the articles being discussed the HIV prevalence is generally high, it is likely that in these articles there is an underestimation of the number of spinal cord lesions caused primarily and secondarily by $\mathrm{HIV}^{20,23}$ (Table 4).

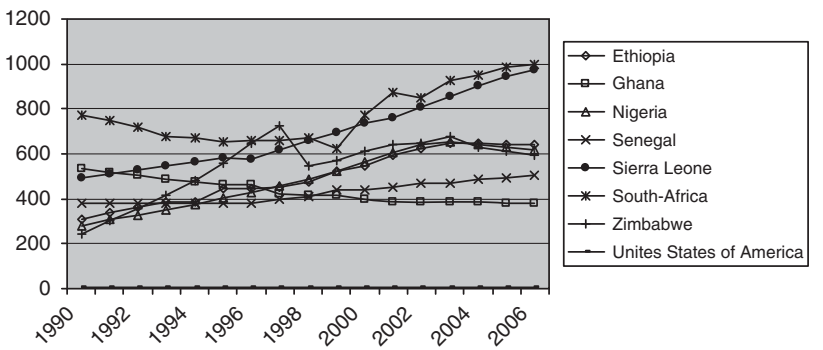

Figure 5 Prevalence of tuberculosis per 100000 inhabitants from the year 1990 until $2006 .^{21}$

The denomination 'myelitis' comprises both infectious myelitis and acute transverse myelitis. Magnetic resonance imaging, which has an important diagnostic role in Western countries was seldom available in the studies consulted ${ }^{20}$ (Table 3 ).

Acute transverse myelitis was withheld as the most common cause of myelitis both in Ghana, Nigeria and Zimbabwe. ${ }^{15-17}$ Only in Ethiopia, where a routine HIV screening was made, HIV-infection was indicated as the most common cause. ${ }^{14}$ However, both vacuolar myelopathy and infections secondary to HIV are lumped under the denominator 'myelitis because of HIV'.

Another cause of infectious myelitis is human T-cell lymphotropic virus type 1 associated myelopathy or tropical spastic paraparesis. Tropical spastic paraparesis is a slowly progressive myelopathy caused by human T-cell lymphotropic virus type 1 retrovirus but when presenting (sub-) acutely it can be difficult to differentiate from acute transverse myelitis. It is only diagnosed in the article from Ethiopia although it is not clear on which criteria the diagnosis was based ${ }^{14}$ (Table 3).

Neoplasm is the second cause of paralysis. Neoplasm refers to both primary tumors such as meningiomas and to metastases of prostate, lung and breast cancer (Table 5).

Malignancies are also in the United States an important cause of non-traumatic SCI ${ }^{18}$ (Figure 4).

Degenerative spinal disease is a large category comprising several types of disorders. There is no clear explanation to the fact that in the article from Ogunniyi et al. ${ }^{16}$ from Nigeria there is such an important number of degenerative diseases.

In the United States, degenerative diseases and specifically spinal canal stenosis together with neoplasms are the most important causes of non-traumatic $\mathrm{SCI}^{19}$ (Figure 4).

\section{Other epidemiological data}

In traumatic SCI, the male-female ratio is much higher than in nontraumatic causes. This can partly be explained assuming that only a minority of the working population are women and therefore are less prone to traffic accidents and falls. However, also in non-traumatic SCI the number of men is higher than the number of women (Figures 6 and 7).

In the worldwide systematic review of Van den Berg et al., ${ }^{1}$ a higher male-female ratio in traumatic than in non-traumatic SCI is also mentioned.

Average age in non-traumatic SCI seems to be higher than in traumatic SCI (Table 2). In American literature, average age is 38.6 years for traumatic spinal cord lesions and 61.2 years for nontraumatic SCI. ${ }^{18,19}$ Paraplegia outnumbers tetraplegia both in the traumatic and the non-traumatic group. In reviews from Ackery et $a .^{2}$ and Wyndaele and Wyndaele ${ }^{3}$ paraplegia accounts for $55 \%$ up to $75 \%$ of the SCI. 
Table 4 Socioeconomic data from the World Health Organization and from the United Nations Development Program (2006) ${ }^{21,23}$

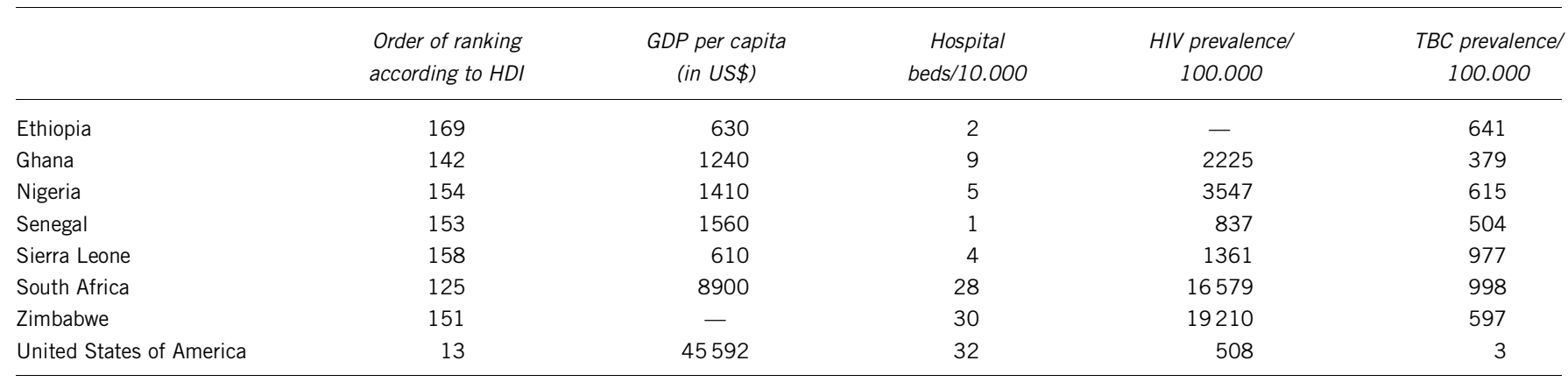

Abbreviations: HDI, Human Development Index from the United Nations Development Program; HIV, human immunodeficiency virus; TBC, tuberculosis.

Table 5 Part of neoplasms in non-traumatic SCI

\begin{tabular}{llccr}
\hline \multirow{2}{*}{ Country } & Authors & Neoplasms (\%) & \multicolumn{2}{c}{ Of which } \\
\cline { 4 - 5 } & & & Primary (\%) & Metastases (\%) \\
& & 23.90 & 8.50 & 15.40 \\
Ethiopia & Zenebe $^{14}$ & 14.10 & 9.40 & 4.70 \\
Ghana & Nyame $^{15}$ & 15.40 & 1.90 & 13.50 \\
Nigeria & Ogunniyi et al. $^{16}$ & 28.00 & 19.90 & 8.10 \\
Zimbabwe & Parry et al. ${ }^{17}$ & & & \\
\hline
\end{tabular}

Abbreviation: SCl, spinal cord injury.

The number of complete lesions reported as mentioned in Table 2 is high in comparison with the $50 \%$ stated by Wyndaele and Wyndaele ${ }^{3}$ The National SCI Database (NASCIS III) cited by Ackery et al. ${ }^{2}$ also shows $50 \%$ complete lesions (Table 2 ).

Recommendations for the collection of data in the future The lack of data in combination with not collecting the data in a uniform way has hampered this study. In order to support and facilitate injury prevention, there is a need for standardized reporting and registration of SCI worldwide.

Trauma registration data sets have been proven to be possible and useful in SSA. ${ }^{24}$

Data sets more specific to SCI were, however, required and an international meeting on SCI data collection and analysis occurred in 2002, before the combined ASIA and International Spinal Cord Society (ISCoS) meeting in Vancouver, Canada. The results of this meeting were presented by Biering-Sørensen, De Vivo et al. ${ }^{25,26}$ They described the International Spinal Cord Injury Core Data Set to standardize the collection and reporting of information on SCI as a basis for future studies of SCI.

Members of the Executive Committee of the International SCI Standards and Data Sets (ECSCI) have worked with the National Institute of Neurological Disorders and Stroke (NINDS), National Institutes of Health (NIH) and the Common Data Element (CDE) Project to integrate the International SCI Data Sets with the other NINDS CDE resources. Biering-Sørensen et al. ${ }^{27}$ described the collaborative work of the ECSCI and the NINDS CDE Team.

The International Classification of the External Cause of Injury (ICECI) is a tool of the International Classification of Diseases (ICD) family and is designed to improve the precision of coding injury events. It has been shown useful in an epidemiological study of injury prevention. $^{28}$

Lee et al. ${ }^{29}$ evaluated the SCI application of the ICECI in a mixed group of trained and untrained coders to assess agreement, refine

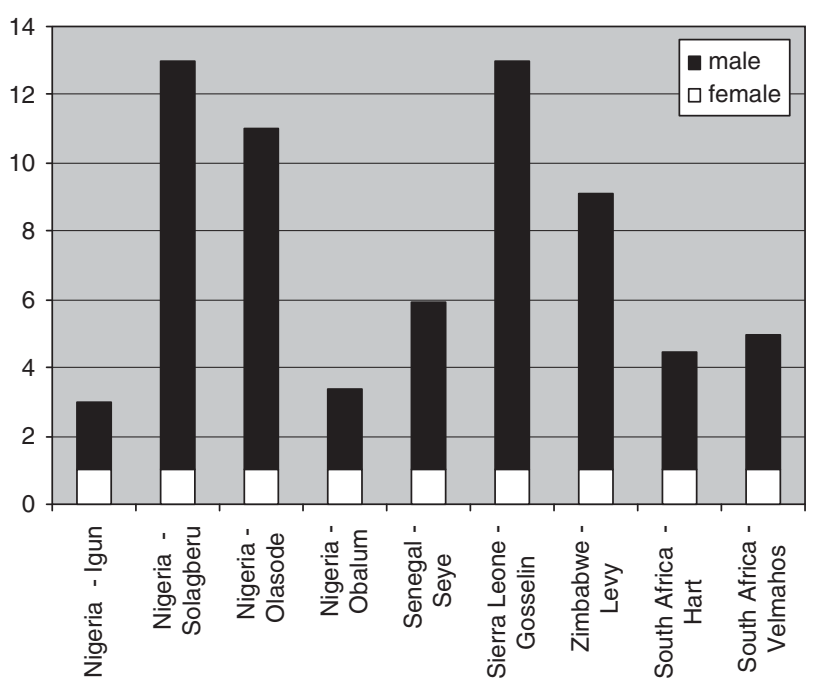

Figure 6 Male-female ratio in traumatic SCl.

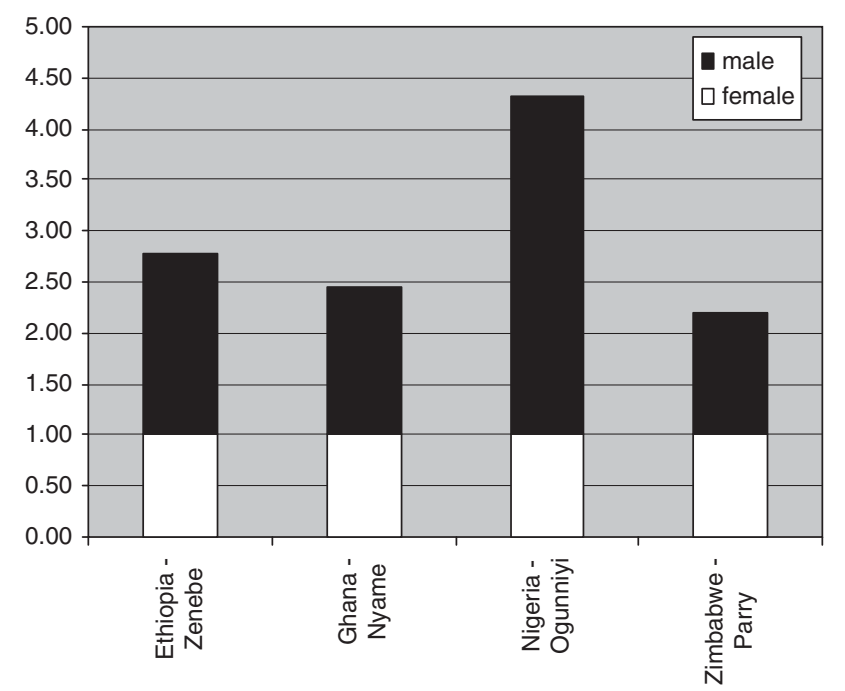

Figure 7 Male-female ratio in non-traumatic SCI.

coding and training methodology. They report that the content validity of the training data set is adequate, however, more cases specific for SCI are required. Increasing familiarity with the ICECI should help us to understand injury mechanism en will help toward injury prevention. ${ }^{4}$ 
Cripps et $a l^{4}$ therefore suggested a data registration tool with a global map for traumatic SCI epidemiology as an initiative of the prevention committee of ISCoS. This is an epidemiological database that will annually be updated and is a living data repository with information to allow valid local and international comparing for use in prevention. The data are presented within the format of a Map of Global Epidemiological trends, which aims to present information in an intuitive manner. ${ }^{29}$ Their current software allows to combine ISCoS core data set reporting with injury coding through the ICECI. ${ }^{4}$

This tool seems promising for reporting and registration of SCI worldwide and will facilitate injury prevention planning. It might be difficult, however, to include all regions. Therefore, the existence and knowledge of this tool should be communicated, its use should be encouraged and access should be facilitated in all countries.

Furthermore, ISCoS is cooperating with the WHO to improve classification systems for use in SCI and prevention. ${ }^{30,31}$

We would like to mention an original initiative to collect data we came across from the Quadpara Association of South Africa. In the project, 'Bags of Hope' rehabilitation centers provided patients on discharge from hospital with a standard package of information and equipment such as bladder catheters in exchange for filling out a questionnaire of data such as cause and nature of their disease. ${ }^{32}$

\section{CONCLUSION}

To our knowledge, this review is the first attempt to make a survey of the etiology of SCIs focused SSA over the last 20 years. Scarcity of data, incomplete information and the lack of a uniform classification are obvious obstacles for definite conclusions.

Within the group of traumatic spinal cord lesions, traffic accidents have a prominent place. Traffic safety should therefore be a point of particular interest. As far as non-traumatic spinal cord lesions are concerned, it is striking that, despite the enormous effort in coping with tuberculosis, it continues to be the main cause. Also, the number of spinal cord lesions as a consequence of HIV and HIV-related diseases is presumed to be underestimated because of the absence of routine screening in most studied countries.

As far as prevention is concerned, the main conclusion to be urged on is that priority should be given to improving traffic safety and coping with tuberculosis and HIV.

Standardized registration of SCI is needed for prevention and further research. The use of the current International SCI core data set should be encouraged as a uniform classification method. The data registration tool proposed by Cripps et al. ${ }^{4}$ and initiated by the ISCoS prevention committee seems very promising for SCI data registration and will facilitate injury prevention. ${ }^{31}$ Therefore, its existence and use should be promoted worldwide.

\section{CONFLICT OF INTEREST}

The authors declare no conflict of interest.

1 Van den Berg M, Castellote J, Mahillo-Fernandez I. Incidence of spinal cord injury worldwide: a systematic review. Neuroepidemiology 2010; 34: 184-192.
2 Ackery A, Tator C, Krassioukov A. A global perspective on spinal cord injury epidemiology. J Neurotrauma 2004; 21: 1355-1370.

3 Wyndaele M, Wyndaele J. Incidence, prevalence and epidemiology of spinal cord injury: what learns a worldwide literature survey? Spinal Cord 2006; 44: 523-529.

4 Cripps R, Lee B, Wing P, Weerts E, Mackay J, Brown D. A global map for traumatic spinal cord injury epidemiology: towards a living data repository for injury preventation. Spinal Cord 2010; 49: 493-501, 1-9 (advanced online presentation).

5 Igun G, Obekpa O, Ugwu B, Nwadiaro N. Spinal injuries in the plateau state, Nigeria. East Afr J Med 1999; 76: 75-79.

6 Solagberu B. Spinal cord injuries in Ilorin, Nigeria. West Afr J Med 2002; 21 . 230-232.

7 Olasode B, Komolafe I, Komolafe M, Olasode O. Traumatic spinal cord injuries in Ile-Ife, Nigeria and its environs. Tropical Doctor 2006; 36: 181-182.

8 Obalum D, Giwa S, Adekoya-Cole T, Enweluzo G. Profile of spinal injuries in Lagos, Nigeria. Spinal Cord 2009; 47: 134-137.

9 Seye S, Sow C, Bassene N, Gueye M, Pouye I. Traumatisme recents du rachis a propos de 496 cas, 30 necropsies. Med Tropicale 1993; 53: 471-477.

10 Gosselin A, Coppotelli C. A follow-up study of patients with spinal cord injury in Sierra Leone. Int Orthop 2005; 29: 330-332.

11 Levy L, Makarawo S, Madzivire D, Bhebe E, Verbeek N, Parry O. Problems, struggles and some success with spinal cord injury in Zimbabwe. Spinal Cord 1998; 36: 213-218.

12 Velmahos G, Degiannis E, Hart C, Souter I, Saadia R. Changing profiles in spinal cord injuries and risk factors influencing recovery after penetrating injuries. J Trauma Injury Infection Critical Care 1995; 38: 334-337.

13 Hart C, Williams E. Epidemiology of spinal cord injuries: a reflection of changes in South African society. Paraplegia 1994; 32: 709-714.

14 Zenebe G. Myelopathies in Ethiopia. East Afr J Med 1995; 72: 42-45.

15 Nyame P. An aetiological survey of paraplegia in Accra. East Afr J Med 1994; 71: 527-530.

16 Ogunniyi A, Shokunbi M, Oluwole O, Adeyinka A, Malomo A, Adebiyi A. Non-traumatic spinal cord diseases in Ibadan, Nigeria: aetiology and prognostic factors. Central Afr J Med 1995; 41: 50-54.

17 Parry O, Bhebe E, Levy L. Non-traumatic paraplegia in a Zimbabwean population - a retrospective study. Central Afr J Med 1999; 45: 114-118.

18 McKinley W. Epidemiology of traumatic spinal cord injury. In: Kirshblum S, Campagnolo D, Delisa J (eds). Spinal Cord Medicine. Lippincott Williams and Wilkins: Philadelphia, USA, 2002, pp 69-81.

19 McKinley W. Nontraumatic spinal cord injury: etiology, incidence and outcome. In: Kirshblum S, Campagnolo D, Delisa J (eds). Spinal Cord Medicine. Lippincott Williams and Wilkins: Philadelphia, USA, 2002, pp 471-479.

20 McKinley W. Infections of the spine and spinal cord. In: Kirshblum S, Campagnolo D, Delisa J (eds). Spinal Cord Medicine. Lippincott Williams and Wilkins: Philadelphia, USA, 2002, pp 498-512.

21 WHO Statistical Information System. In: who.int. http://www.who.int/whosis/data/ (September 2010).

22 Brown KG. Non-traumatic paraplegia in Sub-Saharan Africa. East Afr J Med 1979; 56: 300-310.

23 Human Development Indices: A Statistical update 2008. United Nations Development Programme. In: undp.org. http://hdr.undp.org/en/statistics/ (September 2010).

24 Kobusingye OC, Lett RR. Hospital-based trauma registries in Uganda. J Trauma 2000; 48: 498-502.

25 Biering-Sørensen F, Charlifue S, De Vivo M, Noonan V, Post M, Stripling T et al. International spinal cord injury data sets. Spinal Cord 2006; 44: 530-534.

26 De Vivo M, Biering-Sørensen F, Charlifue S, Noonan V, Post M, Stripling T et al. International spinal cord injury core data set. Spinal Cord 2006; 44: 535-540.

27 Biering-Sørensen F, Charlifue S, Devivo M, Grinnon S, Kleitman N, Lu Y et al. Incorporation of the international spinal cord injury data set elements into the national institute of neurological disorders and stroke common data elements. Spinal Cord 2011; 49: 60-64.

28 Scott D, Harrison J, Purdie D, Bain C, Naiman J, Nixon J et al. The properties of the international classification of the external cause of injury when used as an instrument for injury prevention research. Inj Prev 2006; 12: 253-257.

29 Lee B, Cripps R, Woodman R, Biering-Sørensen F, Wing P, Campbell R et al. Development of an international spinal cord injury prevention module: application of the international classification of external cause of injury to spinal cord injury. Spinal Cord 2010; 48: 498-503.

30 Biering-Sørensen F, Bickenbach J, El Masry W, Officer A, von Groote P. ISCoS-WHO collaboration. International perspictives of spinal cord injury (IPSCI) report. Spinal Cord 2011; 49: 679-683.

31 Prevention Committee - SCI data request. Bonne Lee and Ray Cripps ISCoS International SCI Standards and Data Sets Subgroup. In: iscos.org. http://www.iscos.org.uk/ page. php?content=5 (May 2011).

32 Bags of Hope project.QuadPara Association of South Africa. In: qasa.co.za. http:// www.qasa.co.za (September 2010). 